\title{
Activation Study of Isotopically Enriched Samples During Neutron Time-of-Flight Measurements
}

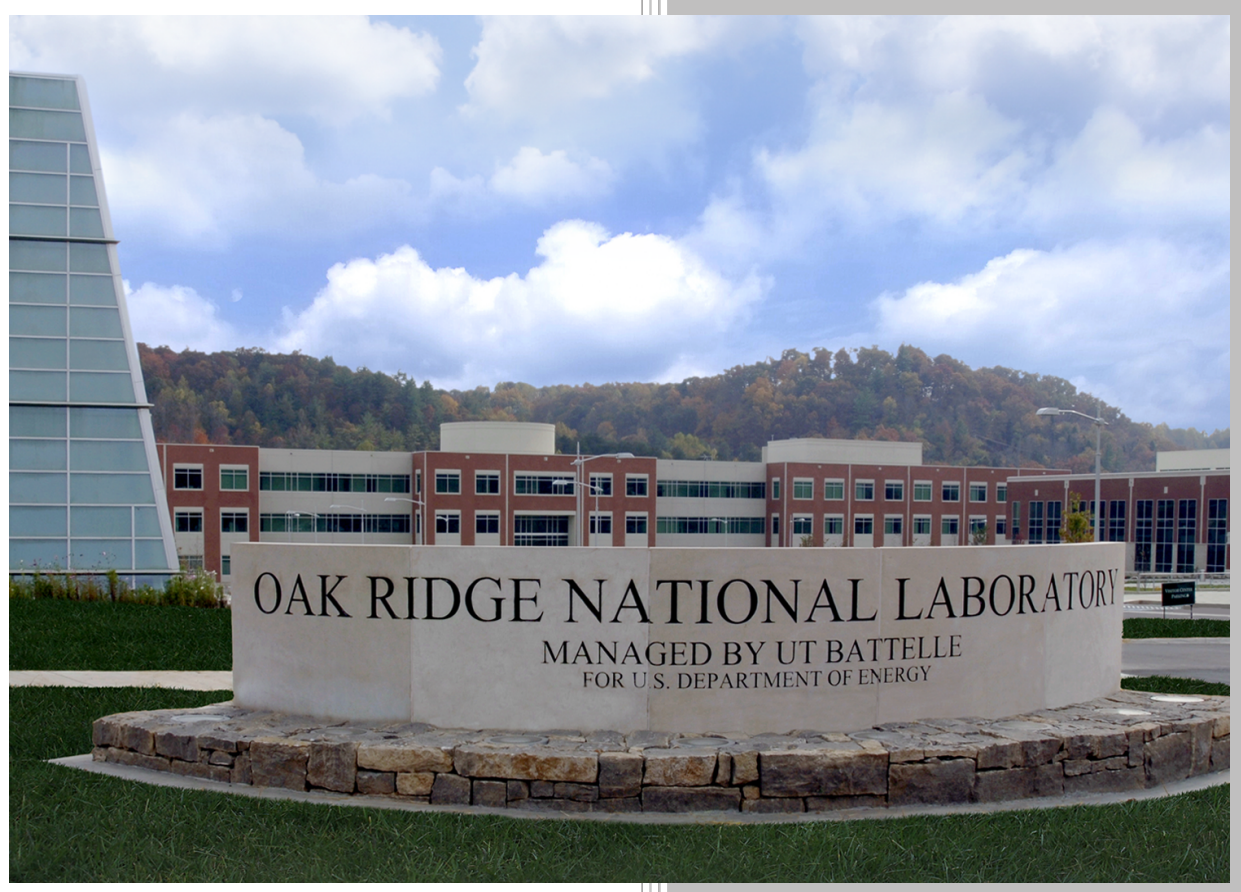

Approved for public release. Distribution is unlimited.

Jesse Brown Klaus Guber Dorothea Wiarda

August 2019 


\section{DOCUMENT AVAILABILITY}

Reports produced after January 1, 1996, are generally available free via US Department of Energy (DOE) SciTech Connect.

Website: www.osti.gov/

Reports produced before January 1, 1996, may be purchased by members of the public from the following source:

National Technical Information Service

5285 Port Royal Road

Springfield, VA 22161

Telephone: 703-605-6000 (1-800-553-6847)

TDD: $703-487-4639$

Fax: 703-605-6900

E-mail: info@ntis.gov

Website: http://classic.ntis.gov/

Reports are available to DOE employees, DOE contractors, Energy Technology Data Exchange representatives, and International Nuclear Information System representatives from the following source:

Office of Scientific and Technical Information

PO Box 62

Oak Ridge, TN 37831

Telephone: 865-576-8401

Fax: 865-576-5728

E-mail: report@osti.gov

Website: http://www.osti.gov/contact.html

This report was prepared as an account of work sponsored by an agency of the United States Government. Neither the United States Government nor any agency thereof, nor any of their employees, makes any warranty, express or implied, or assumes any legal liability or responsibility for the accuracy, completeness, or usefulness of any information, apparatus, product, or process disclosed, or represents that its use would not infringe privately owned rights. Reference herein to any specific commercial product, process, or service by trade name, trademark, manufacturer, or otherwise, does not necessarily constitute or imply its endorsement, recommendation, or favoring by the United States Government or any agency thereof. The views and opinions of authors expressed herein do not necessarily state or reflect those of the United States Government or any agency thereof. 
Reactor and Nuclear Systems Division

\title{
ACTIVATION STUDY OF ISOTOPICALLY ENRICHED SAMPLES DURING NEUTRON TIME-OF-FLIGHT MEASUREMENTS
}

\author{
Jesse Brown \\ Klaus Guber \\ Dorothea Wiarda
}

Date Published: August 2019

\author{
Prepared by \\ OAK RIDGE NATIONAL LABORATORY \\ Oak Ridge, TN 37831-6283 \\ managed by \\ UT-Battelle, LLC \\ for the \\ US DEPARTMENT OF ENERGY \\ under contract DE-AC05-00OR22725
}





\section{CONTENTS}

LIST OF FIGURES $\ldots \ldots \ldots \ldots \ldots \ldots \ldots \ldots \ldots \ldots \ldots \ldots$

LIST OF TABLES $\ldots \ldots \ldots \ldots \ldots \ldots \ldots \ldots \ldots \ldots \ldots$ vii

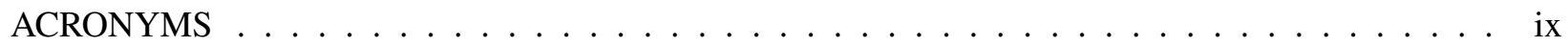

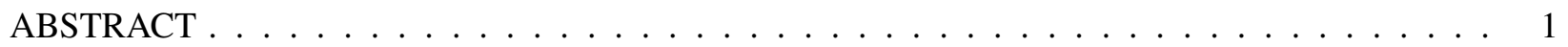

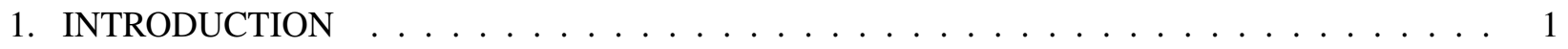

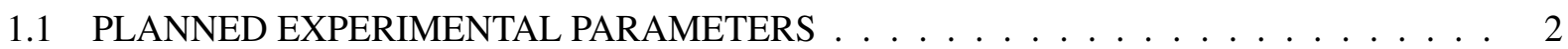

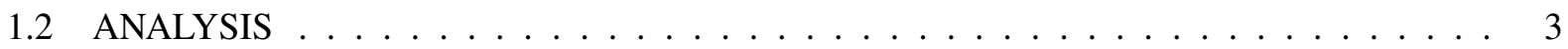

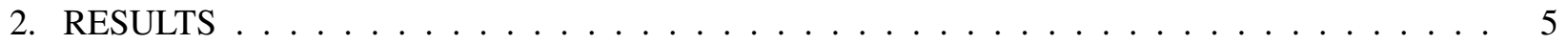

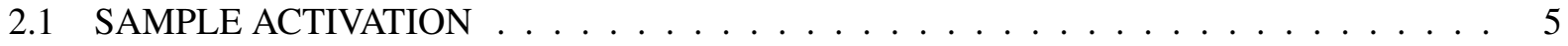

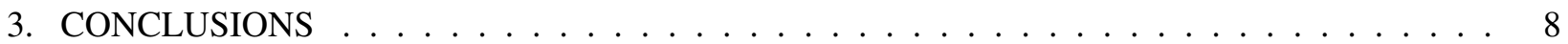

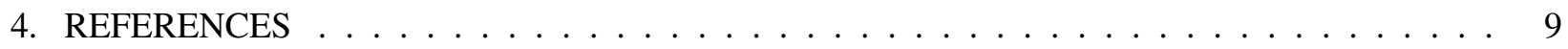





\section{LIST OF FIGURES}

1 Neutron and photon fluxes at GELINA. Fluxes are shown at a $60 \mathrm{~m}$ flight path and an operating current of $60 \mu \mathrm{A}$ without the overlap filters which are typically placed along the flight path to absorb low energy neutrons. . . . . . . . . . . . . . . 3

2 Information flow for a typical sample activation calculation using ORIGEN. The programs used are in red: MAVRIC, COUPLE, and ORIGEN. The sample assay sheet specifies all nuclides present in the sample before beginning irradiation, and the ORIGEN library contains energy-grouped cross sections. MAVRIC is used to calculate the average flux within the volume of each sample, and COUPLE uses the flux and cross section to create a reaction library for ORIGEN. . . . . . . . . . . . . . . . . . . . . 4

3 The process for creating an ORIGEN library from the TENDL-2017 photonuclear library. Modules used from the AMPX code are in red. Data inputs to the modules are included in the arrow shapes. For this study, the process up to the PRILOSEC step was repeated for all nuclides (>2000) and then combined using the AJAX module before being input to

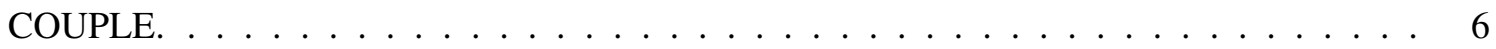

4 Total specific activities $(\mathrm{Bq} / \mathrm{g})$ for oxide samples for the isotopes ${ }^{90,91,92,94} \mathrm{Zr}$ following irradiation in a TOF measurement. Vertical dashed lines represent the points at which the samples—indicated by matching line colors-decay below the $0.6 \mathrm{~Bq} / \mathrm{g}$ limit. The horizontal dashed line represents the limit of activation. Since the activity predicted for the ${ }^{90} \mathrm{Zr}$ sample was well below the limit, it was multiplied by a factor of 100 for this plot to show the activation. . . . . . . . . . . . . . . . . . . .

5 Total specific activities $(\mathrm{Bq} / \mathrm{g})$ for metal samples of the isotopes ${ }^{90,91,92,94} \mathrm{Zr}$. The vertical dashed line represents the point at which the ${ }^{94} \mathrm{Zr}$ sample —indicated by matching black line color-decays below the $0.6 \mathrm{~Bq} / \mathrm{g}$ limit. The horizontal dashed line represents the limit of activation. Only ${ }^{94} \mathrm{Zr}$ was found to be activated beyond the $0.6 \mathrm{~Bq} / \mathrm{g}$ limit for any significant amount of time. . . . . . . . . . . . . . . . . 



\section{LIST OF TABLES}

1 Summary of experimental parameters planned for capture cross section measurement of oxide and metal samples for isotopes ${ }^{90,91,92,94} \mathrm{Zr} \ldots \ldots \ldots$. . . . . . . . . . 3

2 Photonuclear reactions for which the TENDL-2017 library was used as a source of cross

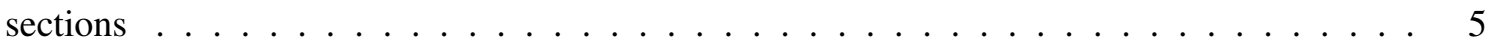

3 The top two largest contributors to radioactivity of each sample following irradiation following a TOF measurement at GELINA . . . . . . . . . . . . . . 7 

ACRONYMS

ORNL Oak Ridge National Laboratory

TOF Time Of Flight

GELINA GEel LINear electron Accelerator

FP Flight Path

ENDF Evaluated Nuclear Data File

NIDC National Isotope Development Center

DOE Department Of Energy 



\begin{abstract}
Over the course of a time-of-flight neutron cross section measurement, the sample isotope(s) of interest are irradiated by neutrons and photons. Ideally, the enriched sample will not have any additional radioactivity after the measurement as compared to the baseline detectable radioactivity $(0.6 \mathrm{~Bq} / \mathrm{g})$ established prior to acquisition of the sample. This document presents the process for estimating the activation of a stable enriched isotope exposed to a mixed photon and neutron source using tools from the SCALE code system developed at Oak Ridge National Laboratory. The report also presents the activation analysis for the isotopes of current interest: ${ }^{90,91,92,94} \mathrm{Zr}$. This information is provided for two sets of $\mathrm{Zr}$ samples: one set of $\mathrm{ZrO}_{2}$ samples, and one set of metal $\mathrm{Zr}$ samples. It was determined that, following measurements at the GELINA linear accelerator facility, all of the enriched $\mathrm{Zr}$ samples would contain less than $0.6 \mathrm{~Bq} / \mathrm{g}$ of radioactivity within 183 days after irradiation.
\end{abstract}

\title{
1. INTRODUCTION
}

The physical models of neutron-nucleus reactions are semi-empirical, meaning that they rely on measured nuclear data to be complete. Due to this reliance, computational tools which model behavior of nuclear systems such as power reactors require nuclear data as input. The accuracy of these computational tools is limited by the accuracy of the input nuclear data. For this reason, nuclear data are carefully evaluated and maintained in nuclear data libraries such as ENDF/B-VII.1 [1], JEFF-3.3 [2], and JENDL-4.0 [3]. The cross sections of many nuclides have been measured, but a significant number of these measurements have various deficiencies. To remedy this, new cross section measurements must be made to reduce uncertainty in existing cross section data and to provide more detailed and accurate cross section data where none previously existed.

The time-of-flight (TOF) method is one of the most accurate methods for measuring cross section as a function of energy. The TOF method typically involves accelerating charged particles to collide with a target consisting of heavy atoms such as Ta or $\mathrm{U}$. When the charged particles interact with these atoms, Bremsstrahlung radiation of varying energies is produced, and Bremsstrahlung photons produce neutrons through $(\gamma, n)$ reactions in the heavy target nuclei. The charged particles are accelerated in a pulsed fashion, and the time at which a burst of neutrons is released from the target can be recorded for each pulse. The time required for the neutrons to fly from the neutron producing target to the sample of interest (typically meters away from the target) is referred to as the TOF. Once the TOF of the neutrons has been determined, the energy of the neutrons can be calculated, and neutron interactions with the sample of interest can be recorded as a function of energy.

Often, samples of interest are isotopically enriched to isolate the observed neutron interactions to a single unique nucleus. Since the enrichment process requires a great deal of time and energy, enriched samples can be quite expensive to fabricate, and experimentalists must exercise caution when using them. Enriched samples can be purchased from the National Isotope Development Center (NIDC), but the cost is often prohibitive. Instead, a researcher may lease the sample for a fraction of the cost.

One of the caveats for the lease is that the sample must have no measurable activity added to it, which has been defined in this case as $0.6 \mathrm{~Bq} / \mathrm{g}$. During the lease process, before the TOF measurement is made, approximately $30 \mathrm{mg}$ of the sample will be removed and tested to establish a baseline for the pre-lease activity of the sample. Following the TOF measurement, another $30 \mathrm{mg}$ of the sample will be removed and 
measured again to ensure that the sample has had no radioactivity added during the lease. Since the preand post-lease measurements are of a destructive nature, the $60 \mathrm{mg}$ portion of the sample must be purchased by the lessee. As TOF measurements require placing an enriched sample of interest in a beam of neutrons and photons, activation of a given sample may become a concern. To predict how a TOF measurement may affect a given sample, the experiment can be modeled with tools from the SCALE code system [4] developed at Oak Ridge National Laboratory (ORNL). This will ensure that when the sample is returned it contains less than $0.6 \mathrm{~Bq} / \mathrm{g}$ of radioactivity.

\subsection{PLANNED EXPERIMENTAL PARAMETERS}

Only a handful of pulsed-source linear accelerators are available to perform cross section measurements, one of which is the Geel linear electron accelerator (GELINA)[5]. Most of these accelerators produce neutron beams in a similar manner. In this case, the GELINA facility will be used for the planned cross section measurements. GELINA is currently operated with an average electron current of approximately 60 $\mu \mathrm{A}$, with energies as high as $150 \mathrm{MeV}$. Pulses of electrons are accelerated linearly to a $\mathrm{U}$ target, producing short, intense bursts of neutrons and photons. The neutrons and photons are collimated down a beam path toward the sample of interest; in this case, samples of ${ }^{90,91,92,94} \mathrm{Zr}$ will be considered. As in-beam photons only add to the unwanted background signal of a measurement, a large brick of $\mathrm{Pb}$ (called a shadow bar) is placed next to the $\mathrm{U}$ target in the direction of the beam path. This significantly reduces the photon flux in the beam path but still allows sufficient neutron flux. The neutron and photon flux spectra for GELINA as calculated by a Monte Carlo N-Particle (MCNP) [6] model are shown in Fig. 1. These fluxes are calculated for a $60 \mathrm{~m}$ flight path (FP) and a $60 \mu \mathrm{A}$ average electron beam current for both the photon and neutron fluxes. To make the activity calculation more conservative, the fluxes were modeled without a neutron overlap filter. The overlap filter is typically a sample of B or Cd placed in the beam to remove low energy neutrons left over from previous neutron bursts that would interfere with the measured TOF count rates (e.g. if we produce bursts at a rate of $400 \mathrm{~Hz}$ we must remove any slow-moving low-energy neutrons in the beam which take longer than $2.5 \mathrm{~ms}$ to travel the FP, otherwise those slow neutron interactions would be recorded at an arbitrary TOF during the next burst). By excluding these filters in the calculation, the flux spectrum includes more low energy neutrons that have an opportunity to create a larger number of radioactive products.

The quantity of interest for upcoming measurements is the capture cross section of ${ }^{90,91,92,94} \mathrm{Zr}$. To measure this quantity the samples will be placed at $60 \mathrm{~m}$ where one of the neutron capture detector setups currently resides at GELINA. As neutrons strike the sample, some are captured by the $\mathrm{Zr}$ nuclei. The excited nuclei following the capture will de-excite, emitting a cascade of photons which can be measured by the capture detector and recorded. The capture cross sections of the $\mathrm{Zr}$ isotopes are quite small, in particular for the even-even isotopes of ${ }^{90,92,94} \mathrm{Zr}$. In fact ${ }^{90} \mathrm{Zr}$ has a closed neutron shell, making it especially resistant to neutron capture. As a result, a sufficient amount $(\sim 20 \mathrm{~g})$ of the samples must reside in the neutron beam for an adequate amount of time to produce a statistically significant number of capture events to be recorded by the detector: typically on the order of 480 hours. However, for this study, a conservative estimate will be made, and it will be assumed that the measurement campaign will last for 960 hours for each sample. The measurement parameters are summarized below in Table 1.

The $\mathrm{ZrO}_{2}$ samples described in Table 1 are easier to obtain for a measurement, so while they are a more cost-friendly option, the oxygen content is undesirable for a neutron cross section measurement, as it introduces greater experimental uncertainty and additional complexity for the cross section evaluator. If it is not prohibitively expensive, another option is to obtain metalized samples, which would provide a 


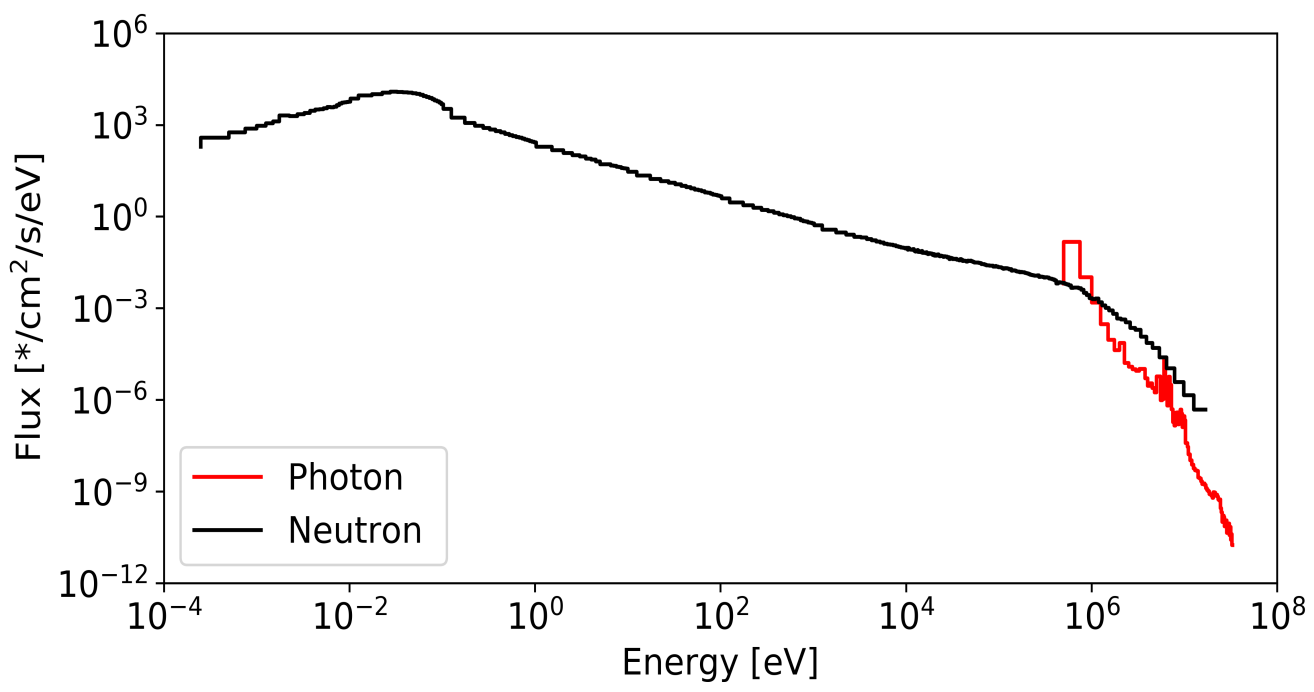

Figure 1. Neutron and photon fluxes at GELINA. Fluxes are shown at a $60 \mathrm{~m}$ flight path and an operating current of $60 \mu \mathrm{A}$ without the overlap filters which are typically placed along the flight path to absorb low energy neutrons.

Table 1. Summary of experimental parameters planned for capture cross section measurement of oxide and metal samples for isotopes ${ }^{90,91,92,94} \mathbf{Z r}$

\begin{tabular}{ccccccccc}
\hline Isotope & Batch No. & Oxide/Metal & Enrichment & Duration & Current & FP & Meas. Type & Mass \\
\hline${ }^{90} \mathrm{Zr}$ & 157493 & Oxide & $96.93 \%$ & 960 hours & $60 \mu \mathrm{A}$ & $60 \mathrm{~m}$ & $\sigma_{\gamma}$ & $20 \mathrm{~g}$ \\
${ }^{91} \mathrm{Zr}$ & 157591 & Oxide & $89.31 \%$ & 960 hours & $60 \mu \mathrm{A}$ & $60 \mathrm{~m}$ & $\sigma_{\gamma}$ & $20 \mathrm{~g}$ \\
${ }^{92} \mathrm{Zr}$ & 189001 & Oxide & $98.06 \%$ & 960 hours & $60 \mu \mathrm{A}$ & $60 \mathrm{~m}$ & $\sigma_{\gamma}$ & $20 \mathrm{~g}$ \\
${ }^{94} \mathrm{Zr}$ & 189191 & Oxide & $98.48 \%$ & 960 hours & $60 \mu \mathrm{A}$ & $60 \mathrm{~m}$ & $\sigma_{\gamma}$ & $20 \mathrm{~g}$ \\
${ }^{90} \mathrm{Zr}$ & 157441 & Metal & $97.65 \%$ & 960 hours & $60 \mu \mathrm{A}$ & $60 \mathrm{~m}$ & $\sigma_{\gamma}$ & $20 \mathrm{~g}$ \\
${ }^{91} \mathrm{Zr}$ & 157570 & Metal & $89.11 \%$ & 960 hours & $60 \mu \mathrm{A}$ & $60 \mathrm{~m}$ & $\sigma_{\gamma}$ & $20 \mathrm{~g}$ \\
${ }^{92} \mathrm{Zr}$ & 157672 & Metal & $95.17 \%$ & 960 hours & $60 \mu \mathrm{A}$ & $60 \mathrm{~m}$ & $\sigma_{\gamma}$ & $20 \mathrm{~g}$ \\
${ }^{94} \mathrm{Zr}$ & 157740 & Metal & $96.07 \%$ & 960 hours & $60 \mu \mathrm{A}$ & $60 \mathrm{~m}$ & $\sigma_{\gamma}$ & $20 \mathrm{~g}$ \\
\hline
\end{tabular}

significantly more chemically pure composition. To prepare for both options, an analysis was performed for each.

\subsection{ANALYSIS}

Neutron activation of materials has been studied extensively. The SCALE program includes a module called ORIGEN which, given a user-specified flux and material specifications, can predict the activity of an irradiated material. To obtain an accurate estimate of the activity of a sample after irradiation, as much detail as possible should be included in the ORIGEN program. The user should specify a flux distribution over energy (seen in Fig. 1), as well as the mass content of every nuclide present in the sample, which is specific to the batch numbers given in Table 1 .

For this effort, an MCNP model of the GELINA neutron production target was used to predict the energy 
profile of the neutron and photon fluxes. The MCNP-simulated neutron flux was then used as input to the program MAVRIC, a Monte Carlo transport module in SCALE, to calculate the energy-dependent flux averaged over the sample. The step with MAVRIC is necessary to ensure that scattered neutrons within the sample are incorporated into the total average neutron flux within the volume of the sample. Once the energy-group averaged neutron fluxes are known, they can be input to COUPLE, which creates a library for ORIGEN to determine the activation of the sample.

As previously mentioned, ORIGEN also requires the sample composition. The enrichment and impurity contents of the samples stored by NIDC are catalogued in detail. This information can be used to select the sample most appropriate for a given experiment. The samples for this study were selected based on criteria of high enrichment and minimal impurities. NIDC designates batch numbers for each enriched sample material. The batches selected for this study are listed in Table 1; the batch numbers can be used to obtain the impurity content.

To run the activation calculation, ORIGEN also requires the cross sections for the relevant nuclides and nuclear reactions. Default group averaged cross sections are distributed as part of the SCALE package and have been calculated and formed into libraries for the SCALE program environment based on the ENDF/B-VII.1 library. These are the neutron cross sections used for the current analysis, as they have been validated by other SCALE modules and benchmark experiments. The input flow for ORIGEN is illustrated in Fig. 2.

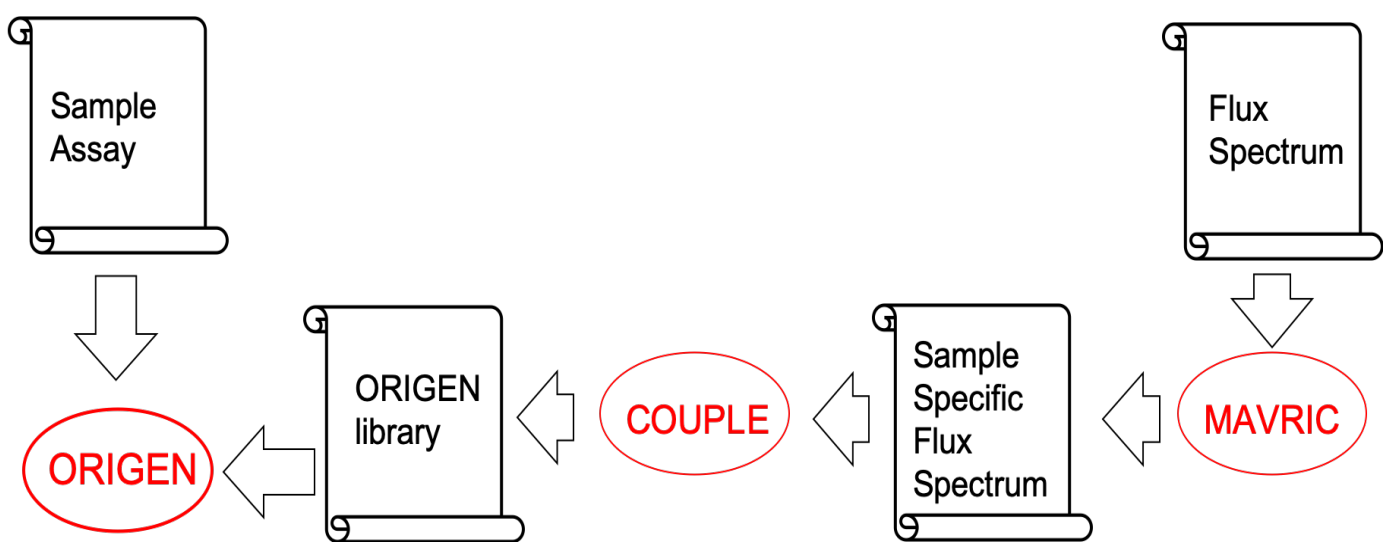

Figure 2. Information flow for a typical sample activation calculation using ORIGEN. The programs used are in red: MAVRIC, COUPLE, and ORIGEN. The sample assay sheet specifies all nuclides present in the sample before beginning irradiation, and the ORIGEN library contains energy-grouped cross sections. MAVRIC is used to calculate the average flux within the volume of each sample, and COUPLE uses the flux and cross section to create a reaction library for ORIGEN.

In its normal operation, ORIGEN calculates neutron activation but does not calculate photon activation. This is largely because photonuclear cross sections are poorly known, and photonuclear reactions have arguably limited applicability to reactors. However, photonuclear reactions may be of importance in the low-level activation of isotopically enriched samples. To overcome this limitation, the TENDL-2017 photonuclear library [7] was used as a source of photonuclear reaction cross sections. Since the ORIGEN program expects a neutron flux, we change the MT numbers of the photon reaction cross sections to analogous reaction MT numbers with incident neutrons and an additional outgoing neutron. In this way we obtain the desired resulting nuclides from the reaction cross sections. The specific reactions used in this 
analysis have been listed in Table 2 where the photon and neutron reactions are described next to one another. It should be noted that the TENDL-2017 library is based on the TALYS [8] program, which gives theoretical predictions of cross sections.

Table 2. Photonuclear reactions for which the TENDL-2017 library was used as a source of cross sections

\begin{tabular}{cccc}
\hline Photon reaction & MT & Corresponding neutron reaction & MT \\
\hline$(\gamma, n)$ & 4 & $(n, 2 n)$ & 16 \\
$(\gamma, 2 n)$ & 16 & $(n, 3 n)$ & 17 \\
$(\gamma, p)$ & 103 & $(n, p n)$ & 28 \\
$(\gamma, \alpha)$ & 107 & $(n, \alpha n)$ & 22 \\
$(\gamma, d)$ & 104 & $(n, d n)$ & 32 \\
$(\gamma, t)$ & 105 & $(n, t n)$ & 33 \\
$(\gamma, n p)$ & 28 & $(n, 2 n p)$ & 41 \\
$(\gamma, n \alpha)$ & 22 & $(n, 2 n \alpha)$ & 24 \\
\hline
\end{tabular}

The cross sections from the TENDL-2017 photonuclear library can be used to compose an ORIGEN library with tools from AMPX, which is part of the SCALE environment. This process is illustrated in Fig. 3. The process for creating an ORIGEN library is repeated for each evaluated nuclear data file (ENDF) in the TENDL-2017 photonuclear library. The POLIDENT module reads the ENDF file and produces pointwise cross sections, in this case from file 3 of the ENDF. Subsequently, the module ZEST reads these pointwise cross sections and returns the user-selected reactions (with modified MT numbers), which are input to the PRILOSEC module. PRILOSEC requires an energy differential flux shape to calculate energy-grouped cross sections; the user's flux shape can be converted to a readable format by the CHARMIN module. Finally, using PRELL, the group structure for the resulting cross section library can be specified and formatted properly for PRILOSEC. PRILOSEC takes all of these inputs and produces a cross section library for each nuclide. The AJAX module is then used to combine all of the nuclides and reactions into a single final cross section library. This cross section library is used by COUPLE, along with the default SCALE decay library, to create an ORIGEN library.

\section{RESULTS}

Once all of the inputs for ORIGEN were defined, the program determined the concentrations of activated products due to neutron and photon interactions. The program also tracked the activity of the isotopes present before the experiment. For example, a $500 \mathrm{ppm}$ impurity of $\mathrm{Rb}$ resides in the ${ }^{91} \mathrm{Zr}$ oxide sample which was selected for this study. Approximately $27 \%$ of naturally occurring $\mathrm{Rb}$ is the isotope ${ }^{87} \mathrm{Rb}$, which decays at a rate of $\approx 8.8 \mathrm{~Bq}$ for a sample of $20 \mathrm{~g}$. The calculated activities of the separate photon activation and neutron activation are summed together, with the exception of pre-existing radioactive nuclides such as the ${ }^{87} \mathrm{Rb}$. This was done for two sets of samples: a set of $\mathrm{ZrO}_{2}$ samples and a set of metalized $\mathrm{Zr}$ samples.

\subsection{SAMPLE ACTIVATION}

The $\mathrm{ZrO}_{2}$ samples selected for these measurements tended to have a greater number of impurities than the metal samples. In terms of the $0.6 \mathrm{~Bq} / \mathrm{g}$ limit, these impurities can be a relatively large source of activity in a sample, both before and after irradiation. The isotope ${ }^{87} \mathrm{Rb}$ is an impurity in the ${ }^{91} \mathrm{Zr}$ oxide sample which by itself maintains the sample activity at a minimum of $0.44 \mathrm{~Bq} / \mathrm{g}$. This is uncomfortably close to the 0.6 


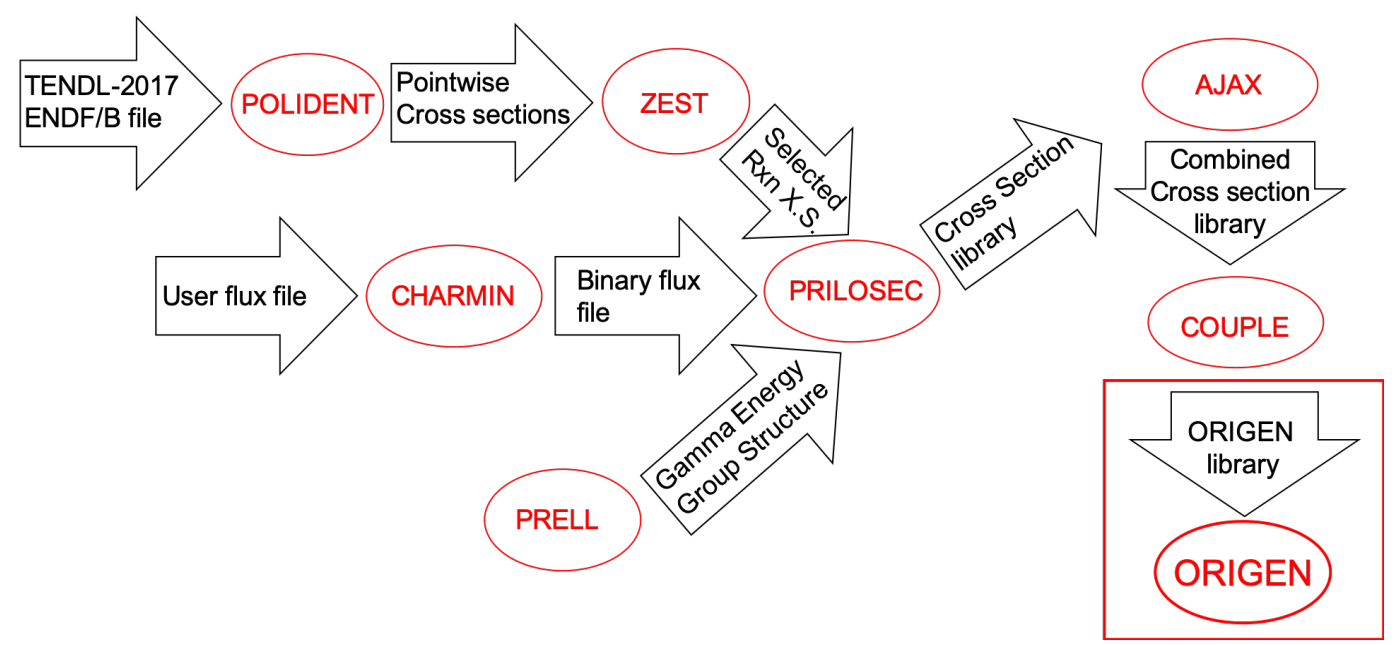

Figure 3. The process for creating an ORIGEN library from the TENDL-2017 photonuclear library. Modules used from the AMPX code are in red. Data inputs to the modules are included in the arrow shapes. For this study, the process up to the PRILOSEC step was repeated for all nuclides (>2000) and then combined using the AJAX module before being input to COUPLE.

$\mathrm{Bq} / \mathrm{g}$ limit. The total anticipated activity for the set of $\mathrm{ZrO}_{2}$ samples considered for this analysis is shown in Fig. 4.

Figure 4 shows that all of the oxide samples are predicted to decay to below the $0.6 \mathrm{~Bq} / \mathrm{g}$ limit within 107 days following a capture cross section measurement at GELINA. The ${ }^{94} \mathrm{Zr}$ sample had the longest lived products, primarily due to the neutron capture reaction on the main isotope: ${ }^{94} \mathrm{Zr}(\mathrm{n}, \gamma){ }^{95} \mathrm{Zr}$. The ${ }^{95} \mathrm{Zr}$ isotope then decays to ${ }^{95} \mathrm{Nb}$ through beta decay. These radioactive isotopes play the dominant role in extending the activity (above $0.6 \mathrm{~Bq} / \mathrm{g}$ ) of the sample to 107 days. It should be noted that photon interactions were predicted to introduce a trivial amount of radioactive products for all of the samples in this study.

For isotopically enriched $\mathrm{Zr}$ samples in metal form, it is assumed again that the sample mass is $20 \mathrm{~g}$. In general, the metal $\mathrm{Zr}$ samples contain fewer impurities, and those impurities contribute less to the overall sample mass. Measuring the cross section using metal $\mathrm{Zr}$ samples would reduce experimental uncertainty as compared to the $\mathrm{ZrO}_{2}$ samples, as there will be less oxygen from which to scatter. Neutron scattering from the sample will already be significant considering the small capture cross section of the $\mathrm{Zr}$ isotopes. Neutron scattering is problematic, as it increases the probability for false capture. False capture is the process in which a neutron scatters from a nucleus in the sample and subsequently captures in a nearby material, producing photons which can be falsely attributed to sample capture. One example of false capture is a neutron scattering from the sample and then capturing in the sample holder material.

Another advantage of measuring metal samples instead of $\mathrm{ZrO}_{2}$ samples is reduced evaluation complexity and uncertainty. During evaluation of $\mathrm{Zr}$ capture cross section data obtained with oxide samples, oxygen content must be taken into account, and the evaluated $\mathrm{Zr}$ and $\mathrm{O}$ cross sections must be correlated. To prepare for the possibility that metal samples are chosen for the planned measurement, the anticipated activities of those samples have been calculated and plotted in Fig. 5.

The two largest contributors to the overall activity of each of the oxide and metal samples following the TOF measurements are shown in Table 3. Photon activation is trivial for all of the $\mathrm{Zr}$ samples. It should be 


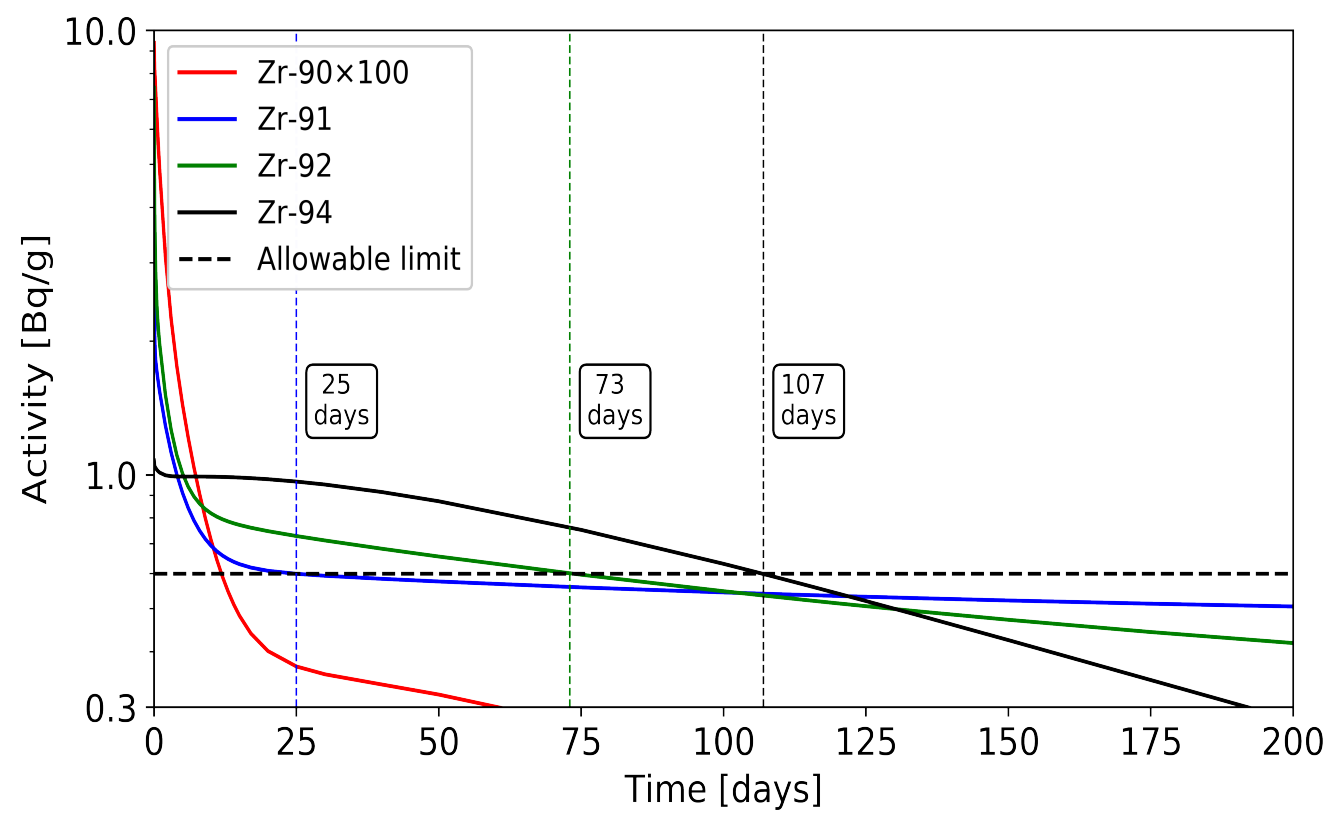

Figure 4. Total specific activities ( $\mathbf{B q} / \mathbf{g})$ for oxide samples for the isotopes ${ }^{90,91,92,94} \mathbf{Z r}$ following irradiation in a TOF measurement. Vertical dashed lines represent the points at which the samples-indicated by matching line colors - decay below the $0.6 \mathrm{~Bq} / \mathrm{g}$ limit. The horizontal dashed line represents the limit of activation. Since the activity predicted for the ${ }^{90} \mathrm{Zr}$ sample was well below the limit, it was multiplied by a factor of 100 for this plot to show the activation.

noted that ${ }^{87} \mathrm{Rb}$ is a leading contributor on two of the oxide samples. For most of the metal samples, it can be seen that ${ }^{97} \mathrm{Zr}$ and ${ }^{97} \mathrm{Nb}$ are the leading contributors to activity. This is due to ${ }^{96} \mathrm{Zr}$ neutron capture, which occurs in all of the samples, and it results in activity which is orders of magnitude less than the 0.6 $\mathrm{Bq} / \mathrm{g}$ limit. The dominant reaction which produces the most significant activity is ${ }^{94} \mathrm{Zr}$ neutron capture, in which ${ }^{94} \mathrm{Zr}$ is the main constituent of the sample.

Table 3. The top two largest contributors to radioactivity of each sample following irradiation following a TOF measurement at GELINA

\begin{tabular}{cc|cccc}
\hline Batch & Isotope & $\mathbf{1}^{\text {st }}$ & Reaction & $\mathbf{2}^{\text {nd }}$ & Reaction \\
\hline 157493 & ${ }^{90} \mathrm{Zr}$ & ${ }^{97} \mathrm{Zr}$ & ${ }^{96} \mathrm{Zr}(n, \gamma)$ & ${ }^{97} \mathrm{Nb}$ & ${ }^{97} \mathrm{Zr} \beta-$ \\
157591 & ${ }^{91} \mathrm{Zr}$ & ${ }^{87} \mathrm{Rb}$ & pre-existing & ${ }^{182} \mathrm{Ta}$ & ${ }^{181} \mathrm{Ta}(n, \gamma)$ \\
189001 & ${ }^{92} \mathrm{Zr}$ & ${ }^{170} \mathrm{Tm}$ & ${ }^{169} \mathrm{Tm}(n, \gamma)$ & ${ }^{87} \mathrm{Rb}$ & pre-existing \\
189191 & ${ }^{94} \mathrm{Zr}$ & ${ }^{95} \mathrm{Zr}$ & ${ }^{94} \mathrm{Zr}(n, \gamma)$ & ${ }^{95} \mathrm{Nb}$ & ${ }^{95} \mathrm{Zr} \beta-$ \\
157441 & ${ }^{90} \mathrm{Zr}$ & ${ }^{97} \mathrm{Zr}$ & ${ }^{96} \mathrm{Zr}(n, \gamma)$ & ${ }^{97} \mathrm{Nb}$ & ${ }^{97} \mathrm{Zr} \beta-$ \\
157570 & ${ }^{91} \mathrm{Zr}$ & ${ }^{97} \mathrm{Zr}$ & ${ }^{96} \mathrm{Zr}(n, \gamma)$ & ${ }^{97} \mathrm{Nb}$ & ${ }^{97} \mathrm{Zr} \beta-$ \\
157672 & ${ }^{92} \mathrm{Zr}$ & ${ }^{97} \mathrm{Zr}$ & ${ }^{96} \mathrm{Zr}(n, \gamma)$ & ${ }^{97} \mathrm{Nb}$ & ${ }^{97} \mathrm{Zr} \beta-$ \\
157740 & ${ }^{94} \mathrm{Zr}$ & ${ }^{95} \mathrm{Zr}$ & ${ }^{94} \mathrm{Zr}(n, \gamma)$ & ${ }^{95} \mathrm{Nb}$ & ${ }^{95} \mathrm{Zr} \beta-$ \\
\hline
\end{tabular}




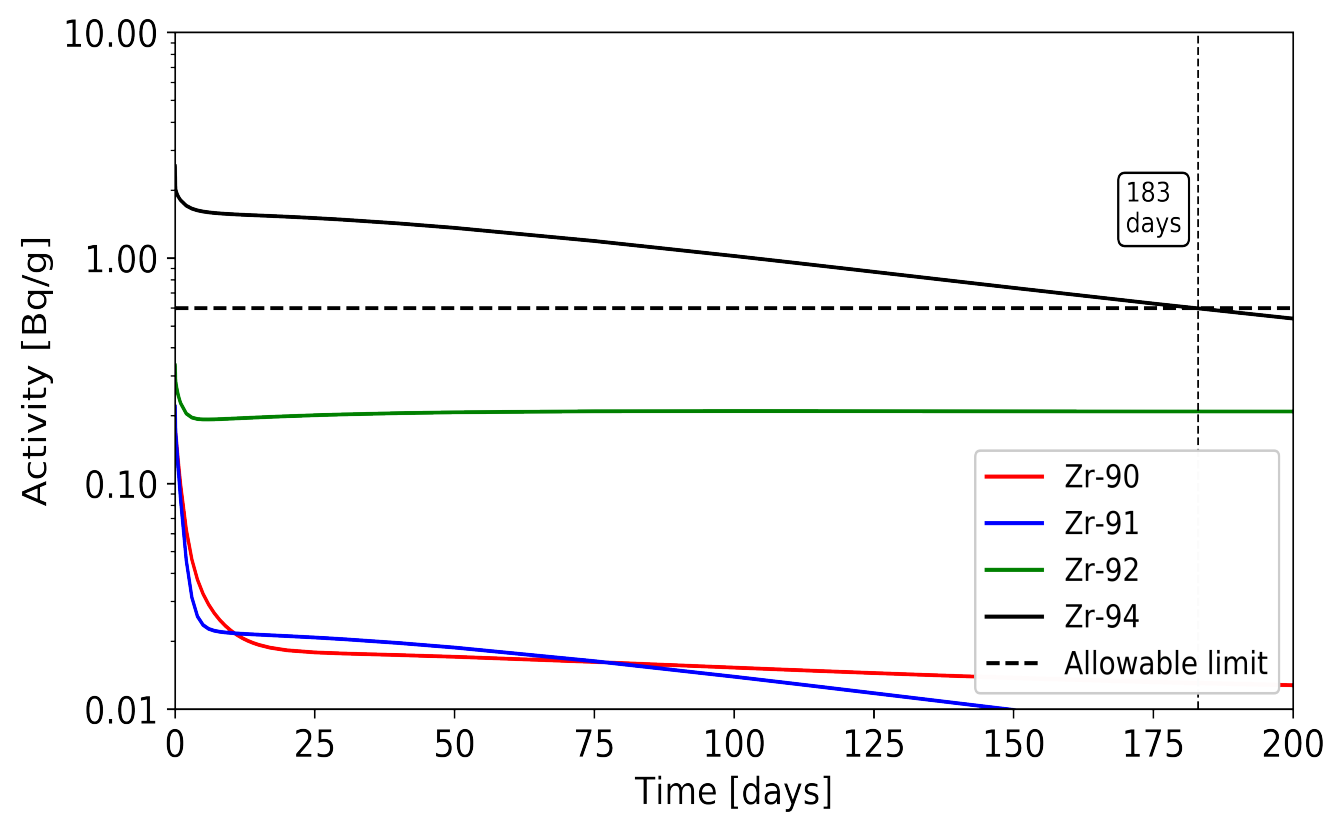

Figure 5. Total specific activities ( $\mathbf{B q} / \mathbf{g})$ for metal samples of the isotopes ${ }^{90,91,92,94} \mathbf{Z r}$. The vertical dashed line represents the point at which the ${ }^{94} \mathrm{Zr}$ sample — indicated by matching black line color-decays below the $0.6 \mathrm{~Bq} / \mathrm{g}$ limit. The horizontal dashed line represents the limit of activation. Only ${ }^{94} \mathrm{Zr}$ was found to be activated beyond the $0.6 \mathrm{~Bq} / \mathrm{g}$ limit for any significant amount of time.

\section{CONCLUSIONS}

Two main conclusions were drawn from this study. The first conclusion is that the activity of an enriched sample exposed to a mixed photon and neutron source can be estimated using tools from AMPX/SCALE. The outline in this report provides a reproducible method that can be applied to any sample. The second conclusion is that the proposed samples for the current measurement would not be activated beyond 183 days in the worst case. To comply with the lease from NIDC, the samples should be maintained for the duration of the typical 1-year lease and returned without any measurable radioactivity added. 


\section{REFERENCES}

\section{References}

[1] M. Chadwick et al., "ENDF/B-VII.1 Nuclear Data for Science and Technology: Cross Sections, Covariances, Fission Product Yields and Decay Data," Nuclear Data Sheets, vol. 112, no. 12, pp. 2887 - 2996, 2011, special Issue on ENDF/B-VII.1 Library. [Online]. Available: http://www.sciencedirect.com/science/article/pii/S009037521100113X

[2] The JEFF-3.3 Evaluated Data Library, OECD NEA, Paris, France, 2017, Accessed: Dec. 27, 2018. [Online]. Available: https://www.oecd-nea.org/dbdata/jeff/jeff33/index.html

[3] K. Shibata et al., "JENDL-4.0: A new library for nuclear science and engineering," J. Nucl. Sci. Technol., vol. 48, no. 1, pp. 1-30, Jan. 2011.

[4] B. T. Rearden and M. A. Jessee, "Scale Code System," Oak Ridge National Laboratory, Oak Ridge, TN, Tech. Rep. ORNL/TM-2005/39, 2018, available from Radiation Safety Information Computational Center as CCC-834.

[5] W. Mondelaers and P. Schillebeeckx, "GELINA, a neutron time-of-flight facility for high-resolution neutron data measurements," Notizario, vol. 11, no. 2, pp. 19-25, Jul. 2006.

[6] C. Werner et al., "MCNP Users Manual - Code Version 6.2," Los Alamos National Laboratory, Los Alamos, NM, Tech. Rep. LA-UR-17-29981, 2017.

[7] D. Rochman, A. J. Koning, J. C. Sublet, M. Fleming et al., "The TENDL library: hope, reality and future," in Proc. of the International Conference on Nuclear Data for Science and Technology, Bruges, Belgium, Sept. 11-16, 2016.

[8] A. Koning and D. Rochman, "Modern nuclear data evaluation with the talys code system," Nuclear Data Sheets, vol. 113, no. 12, pp. 2841-2934, 2012, special issue on Nuclear Reaction Data. [Online]. Available: http://www.sciencedirect.com/science/article/pii/S0090375212000889 


\section{ACKNOWLEDGMENTS}

The authors would like to acknowledge the expert advice from Ian Gauld on the use of the ORIGEN program. This work was supported by the US Department of Energy (DOE) Nuclear Criticality Safety Program, funded and managed by the National Nuclear Security Administration for DOE. 